\title{
Systematic review on cadaveric studies of anatomic anterior cruciate ligament reconstruction
}

\author{
Carola F. van Eck $\cdot$ Kristian Samuelsson • \\ Shail M. Vyas • C. Niek van Dijk • \\ Jon Karlsson • Freddie H. Fu
}

Received: 25 January 2011/ Accepted: 2 May 2011/Published online: 17 May 2011

(C) The Author(s) 2011. This article is published with open access at Springerlink.com

\begin{abstract}
Purpose One of the templates in the development of "anatomic" anterior cruciate ligament (ACL) reconstruction has been basic science studies focusing on comparing various aspects of $\mathrm{ACL}$ reconstruction in order to optimize surgical technique. However, often such papers lack necessary data in the methods section to ascertain the proposed surgical technique as anatomic. The goal of this systematic review was to evaluate basic science studies on anatomic ACL reconstruction.

Methods A systematic electronic search was performed using the MEDLINE and EMBASE databases. Studies that were published from January 1995 to April 2009 were included. Only basic science studies on human cadavers that reported "anatomic" ACL reconstruction and written in English were included. Variation in surgical technique and reporting of surgical description were assessed.

Results Eighteen studies were included in this systematic review. Only the fixation method, graft type and tension pattern were reported in the majority studies. Notchplasty and radiographic documentation were grossly underreported. Other surgical data were reported at best in twothirds of the studies. There was a large variation in the
\end{abstract}

C. F. van Eck · S. M. Vyas · F. H. Fu ( $\square)$

Department of Orthopaedic Surgery, University of Pittsburgh

Medical Center, Kaufmann Building Suite 1011,

3471 Fifth Avenue, Pittsburgh, PA 15213-3221, USA

e-mail: ffu@upmc.edu

C. F. van Eck - C. N. van Dijk

Orthopaedic Research Centre Amsterdam,

Academic Medical Center, Amsterdam, The Netherlands

K. Samuelsson · J. Karlsson

Department of Orthopaedics,

Sahlgrenska University Hospital, Mölndal, Sweden reported surgical techniques among the included studies. Due to the aforementioned, it was not deemed possible to pool data of the included studies.

Conclusion For most variables in the surgical technique description, there was sizeable underreporting resulting in an inability to pool the outcomes. To provide literature that holds up to the current high level of medical research, authors are encouraged to report their surgical technique in a thorough manner, similar to high-level clinical trials. Level of evidence Systematic review, Level II.

Keywords Anatomic - Anterior cruciate ligament . Surgical technique $\cdot$ Systematic review

\section{Introduction}

Recently, there has been a growing interest in more anatomic approach to anterior cruciate ligament (ACL) reconstruction. The reason for the new found interest lies both in the history and in the present. Past studies have shown that ACL reconstruction does not protect the knee from developing osteoarthritis and that it does not fully restore normal knee kinematics $[15,25]$. As a result, there has been a rapid development during the past decade in terms of surgical techniques for ACL reconstruction, especially the doublebundle ACL reconstruction and the utilization of the accessory medial portal operative technique. Both surgical techniques increase the possibility to replicate native anatomy and both promote anatomic ACL reconstruction. Basic science studies, for instance cadaver studies, have shown benefits with anatomic ACL reconstruction, and these studies are therefore used as a template when implementing the new surgical techniques. There is hope that more "anatomic" ACL reconstruction techniques will better 
restore normal knee kinematics and reduce the incidence of osteoarthritis after ACL reconstruction. However, utilization of the term "anatomic" with regard to ACL reconstruction can be misleading. It has been used interchangeably with several surgical techniques, especially double-bundle ACL reconstruction. The latter is a step closer to native anatomy, but can still be performed non-anatomically. A detailed definition of the anatomic ACL reconstruction has recently been proposed: the functional restoration of the ACL to its native dimensions, collagen orientation, and insertion sites [26]. The definition provides a means to evaluate the anatomic degree of today's clinical trials and basic science studies on ACL reconstruction. The goal of the present systematic review was to assess the current basic science studies on anatomic ACL reconstruction, evaluating the reconstructive methods applied, in order to determine whether these data are sufficient to ascertain the surgical technique as anatomic. Therefore, a descriptive analysis of the reporting of surgical data was performed. We hypothesized that the description of surgical technique would be insufficient and potentially limiting the possibility to extrapolate the results to a clinical setting.

\section{Materials and methods}

This systematic review was conducted following the guidelines provided by the Cochrane Handbook [9].

Criteria for considering studies for this review

\section{Types of studies}

Cadaver studies reporting on anatomic ACL reconstruction, both single- and double-bundle techniques, were included in this study.

\section{Types of specimens}

Only studies describing surgical techniques involving human cadavers were eligible for inclusion.

\section{Types of interventions}

Since there were no readily available criteria for anatomic ACL reconstruction, we chose to include all papers in which the authors stated that the reconstructive surgical procedure they applied was "anatomic." Only recently, there has been a first attempt to define "anatomic" ACL reconstruction [26]. We therefore deemed it unfair to include all papers on ACL reconstruction and assess their anatomic degree, since most authors never claimed their technique to be "anatomic." Studies focusing on describing the anatomy, without performing any reconstruction, were excluded. Studies, in which biomechanical properties were tested on solely the femoral or tibial side, without reconstructing the other side, were excluded.

\section{Types of outcome measures}

A descriptive review of the reporting of a variety of surgical data was performed with the utilization of a work sheet. Demographic data obtained from the included papers were the following authors, year, and journal of publication. The data from the applied surgical technique obtained from the included papers are displayed in Table 1 . The data were recorded as either "yes reported," or "not reported." In addition, if an item was scored as "yes reported," more specific data were collected when possible for the purpose of pooling.

Search strategy

A systematic electronic search was performed using the MEDLINE and EMBASE databases. Studies that were published from January 1995 to April 2009 were included. The search was carried out in April 2009. The year 1995 was chosen as the starting date, since we are not aware of the term "anatomic" being used for ACL reconstruction before the year 1998 and a 3-year margin was added. The following key search terms were used in all fields: "anterior cruciate ligament" OR "ACL" AND "anatomic" OR "anatomical" AND "reconstruction" OR "surgery" AND "1995:2009" (See "Appendix" for complete search string). Only articles written in English were included. Finally, the reference lists of the selected studies were investigated to identify additional studies that were not found through our electronic search.

Data collection and analysis

\section{Selection of studies}

From the abstracts, two authors independently selected relevant studies for full-text review. Studies were also included for full review if the abstract did not provide enough data to make an accurate immediate decision. For inclusion in the review, two authors independently analyzed the full texts using the previously described criteria. The analysis was not performed in a blinded fashion, i.e., blacking out authors, title, and so on. Disagreement between the two reviewers was resolved by consensus.

\section{Data extraction and management}

The data were extracted from the included papers, according to a predefined standardized data sheet. The data 
Table 1 Demographic and surgical data recorded from included studies

\begin{tabular}{|c|c|}
\hline \multicolumn{2}{|l|}{ Author $1-7$} \\
\hline Year of publication & Proof of tunnel placement provided \\
\hline Journal of publication & $\begin{array}{l}\text { Placement of the tibial tunnel at } \\
\text { fixed distance from another } \\
\text { anatomic structure }\end{array}$ \\
\hline $\begin{array}{l}\text { Use of an accessory medial } \\
\text { portal }\end{array}$ & $\begin{array}{l}\text { Placement of the tibial tunnel at } \\
\text { fixed distance from another } \\
\text { anatomic structure }\end{array}$ \\
\hline $\begin{array}{l}\text { Visualization of the tibial } \\
\text { insertion site }\end{array}$ & Based on patient characteristics \\
\hline $\begin{array}{l}\text { Visualization of the femoral } \\
\text { insertion site }\end{array}$ & Graft type that was used \\
\hline $\begin{array}{l}\text { Visualization of the lateral } \\
\text { intercondylar and bifurcate } \\
\text { ridge }\end{array}$ & Use of fluoroscopy \\
\hline $\begin{array}{l}\text { Measuring the tibial insertion } \\
\text { site }\end{array}$ & Use of navigation \\
\hline $\begin{array}{l}\text { Measuring the femoral insertion } \\
\text { site }\end{array}$ & Tibial fixation method \\
\hline $\begin{array}{l}\text { Measuring the dimensions of } \\
\text { the femoral intercondylar } \\
\text { notch }\end{array}$ & Femoral fixation method \\
\hline Performing wall or notchplasty & $\begin{array}{l}\text { Use of a different tension pattern } \\
\text { for the anteromedial and } \\
\text { posterolateral bundle graft }\end{array}$ \\
\hline $\begin{array}{l}\text { Use of o'clock face for femoral } \\
\text { tunnel position }\end{array}$ & Use of postoperative radiography \\
\hline $\begin{array}{l}\text { Flection angle during femoral } \\
\text { drilling }\end{array}$ & Use of postoperative MRI \\
\hline $\begin{array}{l}\text { Placement of the tibial tunnel in } \\
\text { ACL footprint }\end{array}$ & Use of postoperative CT-scan \\
\hline $\begin{array}{l}\text { Placement of the femoral tunnel } \\
\text { in ACL footprint }\end{array}$ & $\begin{array}{l}\text { Use of postoperative three- } \\
\text { dimensional CT-scan }\end{array}$ \\
\hline
\end{tabular}

sheet included a column for all the data, as well as an additional column for comments. The first author validated the extracted data by processing the included studies once again after data extraction.

\section{Results}

There were 740 search results on MEDLINE and 357 on EMBASE, using the previously described search criteria (Fig. 1). From these 1,097 studies, 1,002 were excluded based on the abstracts, as they did not meet the inclusion criteria. Most of the excluded studies were clinical trials or not written in English. From the 95 remaining papers, observer 1 initially included 19 papers and observer 2 included 21 papers. Of those papers, 18 were selected by both observers and the remaining 4 were discussed an excluded after consensus. Therefore, 18 papers were selected for final

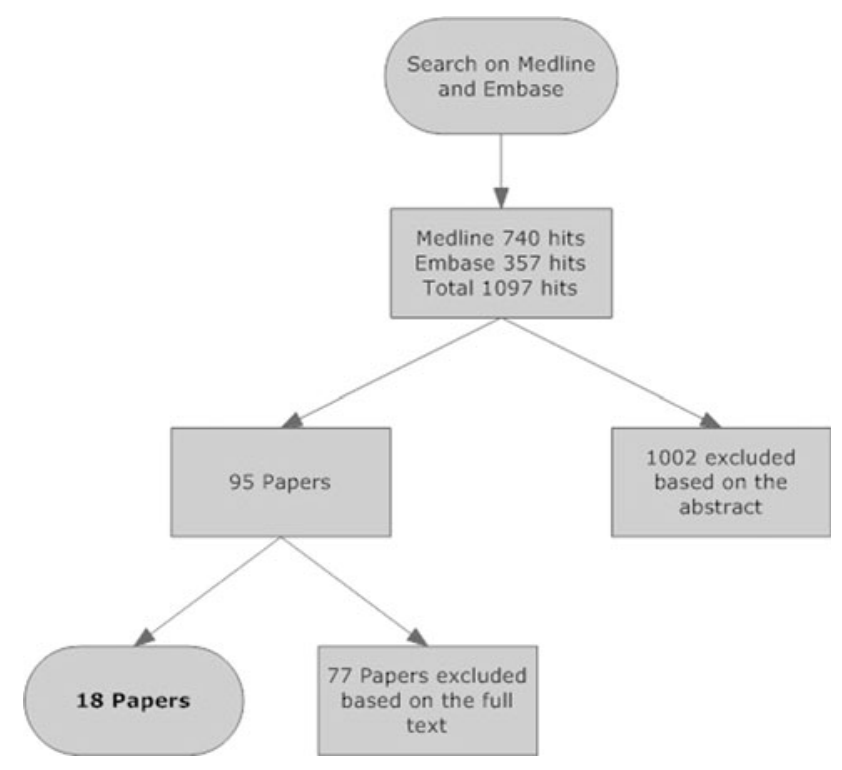

Fig. 1 Flow diagram of the selection process of the studies included in this systematic review

inclusion in the systematic review $[1,2,6-8,10,12,17,18$, 20-22, 24, 30, 31, 33, 36, 37]. The other 77 studies were mostly excluded because they did not claim that their reconstructive technique was anatomic. All papers were published between 2002 and 2009, with an average publication year of 2006. They were written by 17 different first authors and published in 7 different journals. Those journals were the following: American Journal of Sports Medicine (7), Knee Surgery Sports Traumatology Arthroscopy (3), Journal of Bone and Joint Surgery-American (2), ArthroscopyJournal or Arthroscopy and Related Research (2), Clinics (2), Archives of Orthopaedic and Trauma Surgery (1), and Clinical Orthopaedics and Related Research (1).

Whether the recorded surgical data were reported or not reported in the included papers is displayed in Table 2. The majority of the papers used double-bundle reconstruction (77.8\%) and the remainder single-bundle reconstruction. Mechanical testing with the use of a robotic testing system was the method in many studies. An accessory medial portal, in addition to the standard anterolateral and anteromedial portal, was used in $28 \%$ of the studies. Of the remaining $72 \%$, most used a two-portal technique, while $30 \%$ used an open approach. The tibial and femoral insertion sites were visualized in approximately two-thirds of the included studies, whereas visualization of the bony ridges was not reported in any of them. None of the authors reported the dimensions of the tibial and/or femoral insertion site, or the femoral intercondylar notch. Notchplasty was performed in $6 \%$ of the studies. Sixty-seven percent and 56\% of the studies reported placing the tibial and femoral tunnels in the tibial and femoral ACL insertion site area, respectively. Fifty-six percent of them also 
Table 2 Reporting of surgical data in included reviews

\begin{tabular}{|c|c|c|}
\hline & $\begin{array}{l}\text { Reported } \\
(\%)\end{array}$ & $\begin{array}{l}\text { Not } \\
\text { reported } \\
(\%)\end{array}$ \\
\hline Use of an accessory medial portal & 27.8 & 72.2 \\
\hline Visualization of the tibial insertion site & 61.1 & 38.9 \\
\hline Visualization of the femoral insertion site & 66.7 & 33.3 \\
\hline $\begin{array}{l}\text { Visualization of the lateral intercondylar and } \\
\text { bifurcate ridge }\end{array}$ & 0 & 100 \\
\hline Measuring the tibial insertion site & 0 & 100 \\
\hline Measuring the femoral insertion site & 0 & 100 \\
\hline $\begin{array}{l}\text { Measuring the dimensions of the femoral } \\
\text { intercondylar notch }\end{array}$ & 0 & 100 \\
\hline Performing wall or notchplasty & 5.6 & 94.4 \\
\hline Use of o'clock face for femoral tunnel position & 50 & 50 \\
\hline Flection angle during femoral drilling & 22.2 & 77.8 \\
\hline Placement of the tibial tunnel in ACL footprint & 66.7 & 33.3 \\
\hline $\begin{array}{l}\text { Placement of the femoral tunnel in ACL } \\
\text { footprint }\end{array}$ & 55.6 & 27.8 \\
\hline Proof of tunnel placement provided ${ }^{\dagger}$ & 55.6 & 27.8 \\
\hline $\begin{array}{l}\text { Placement of the tibial tunnel at fixed distance } \\
\text { from another anatomic structure }\end{array}$ & 44.4 & 55.6 \\
\hline $\begin{array}{l}\text { Placement of the tibial tunnel at fixed distance } \\
\text { from another anatomic structure }\end{array}$ & 38.9 & 61.1 \\
\hline Graft type that was used ${ }^{\dagger}$ & 94.4 & 5.6 \\
\hline Use of fluoroscopy & 11.1 & 88.9 \\
\hline Use of navigation & 11.1 & 88.9 \\
\hline Tibial fixation method $^{\dagger}$ & 100 & 0 \\
\hline Femoral fixation method ${ }^{\dagger}$ & 100 & 0 \\
\hline $\begin{array}{l}\text { Use of a different tension pattern for the } \\
\text { anteromedial and posterolateral bundle graft }\end{array}$ & 78.6 & 21.4 \\
\hline Use of postoperative radiography & 16.7 & 83.3 \\
\hline Use of postoperative MRI & 0 & 100 \\
\hline Use of postoperative CT-scan & 0 & 100 \\
\hline Use of postoperative three-dimensional CT-scan & 0 & 100 \\
\hline
\end{tabular}

${ }^{\dagger}$ More specific data are provided in additional tables

* For double-bundle techniques only

provided visual proof of this in their manuscript in the form of a diagram, arthroscopic pictures, radiographs, MRI, CT scan, or in another way (Table 3). Other ways included reference to previous publications with visual proof, fluoroscopic images, and gross cadaveric dissection photographs. The position of tibial tunnel was reported to be at a fixed distance from another anatomic structure in $44 \%$ of all studies; this was $39 \%$ of all included studies for the femoral side. On the tibial side, the authors used the medial tibial spine, PCL insertion site, proximal border of the tibia, and the lateral meniscus for guidance of tibial tunnel placement. On the femoral side, various authors used the lateral intercondylar notch wall or an offset guide. Half of the authors clarified or determined their femoral tunnel
Table 3 Proof of tunnel placement in the native ACL footprint

\begin{tabular}{lcc}
\hline & Shown $^{\dagger}(\%)$ & Not shown $(\%)$ \\
\hline Diagram & 72.2 & 27.8 \\
Pictures & 0 & 100 \\
Radiographs & 11.1 & 88.9 \\
MRI & 0 & 100 \\
CT & 11.1 & 88.9 \\
3D CT & 5.6 & 94.4 \\
Other & 11.1 & 88.9 \\
Multiple of the above & 11.1 & 88.9 \\
\hline$\%$ of papers that use this methods to show their tunnel positions
\end{tabular}

Table 4 Fixation methods used for anatomic ACL reconstruction

\begin{tabular}{llc}
\hline Fixation method & Femoral side (\%) & Tibial side (\%) \\
\hline Suspensory fixation & 50 & 0 \\
Post & 11.1 & 27.8 \\
Metal interference screw & 5.6 & 5.6 \\
Bio-absorbable interference & 5.6 & 11.1 \\
$\quad$ screw & & \\
Staple & 0 & 11.1 \\
Washer lock & 0 & 5.6 \\
Other & 5.6 & 22.0 \\
\hline
\end{tabular}

positions using the 'o'clock reference, ranging from 9.00 to 11.00 or 1.00 to 3.00 o'clock. The knee flection during drilling of the femoral tunnels was reported in $22 \%$ of the papers, and all reported it to be 90 degrees. Navigation was used in $11.1 \%$ of studies and the same percentage used fluoroscopic assistance. The graft type was reported in over $94 \%$ of the studies and included hamstrings (55.6\%), bonepatellar tendon-bone $(5.6 \%)$, quadriceps tendon $(5.6 \%)$, fresh frozen allograft $(16.7 \%)$, or other sources $(11.1 \%)$. One study used an artificial graft. Graft fixation type of both the tibial and the femoral side was reported in all papers and constituted mostly of a screw and post on the tibia and suspensory fixation for the femur (Table 4). For the double-bundle reconstruction procedures, the two bundles (AM and PL) were tensioned separately in $79 \%$ of the studies performing double-bundle reconstruction. Various combinations of tensioning patterns were used. The knee flection angle for PL graft fixation ranged from 0 to 20 degrees, but was most often 15 degrees. For the AM, it ranged from 0 to 75 degrees, but was mostly 60 degrees. For the single-bundle reconstruction, the tension patterns ranged from 0 to 30 degrees of knee flection. Imaging techniques were sparsely used in these cadaveric trials, with only $17 \%$ for standard radiographs and no standard use of MRI or CT. 

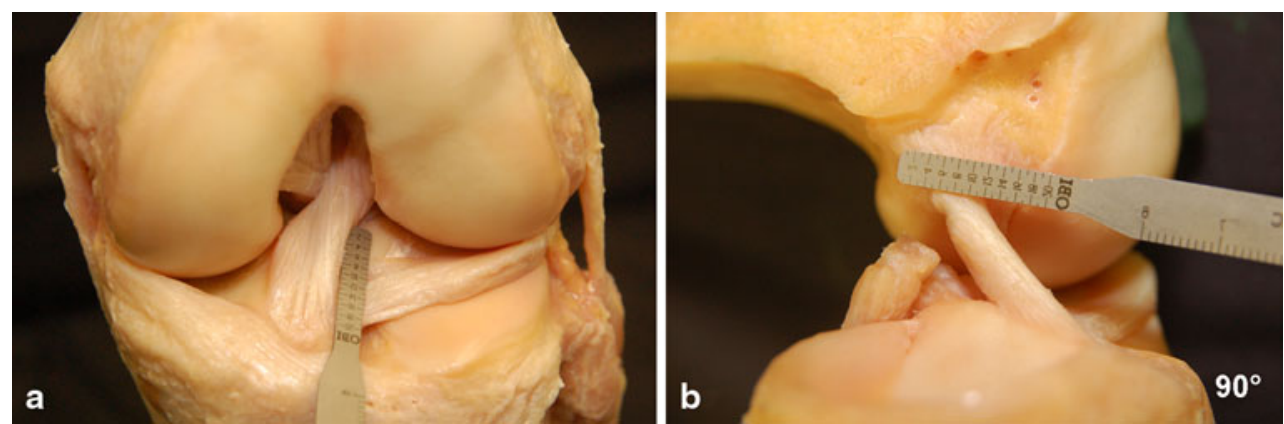

Fig. 2 Cadaveric left knee specimen showing the ability to clearly identify the ACL and its insertion sites. The tibial (a) and femoral (b) insertion site can be measured using an arthroscopic ruler.
Although this method is relatively new, and no reliability data are currently available, it gives the surgeon a good estimate of the insertion site size of the patient

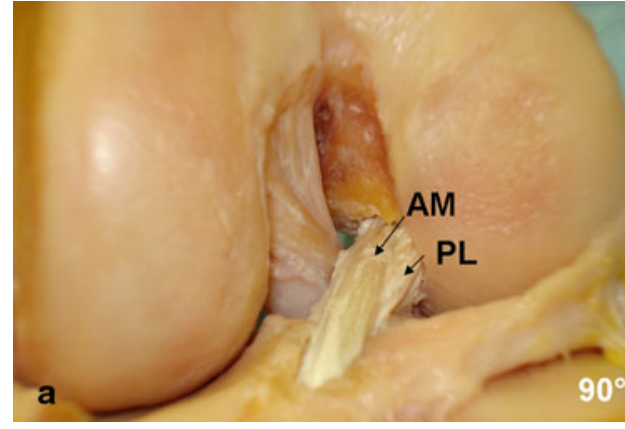

Fig. 3 Cadaveric left knee specimen. The anteromedial $(A M)$ and posterolateral $(P L)$ bundle grafts and tunnel locations are marked. a Situation after anatomic double-bundle ACL reconstruction. This

\section{Discussion}

In this study, it was hypothesized that the description of the surgical technique would be insufficient, potentially limiting the possibility to extrapolate the results to a clinical setting. The hypothesis was affirmed in that some of the surgical technique descriptors were poorly reported such as visualizing of the insertion sites and bony landmarks and placing the tunnels in the native insertion site area, as well as providing visual proof of tunnel placement. Only twothirds of the included studies visualized the tibial and femoral insertion sites and none measured the insertion sites or visualized the bony ridges. This was a smaller percentage than a systematic review evaluating these same or similar factors in clinical trials [29]. The same was true for placement of the tunnels in the native insertion site area, which was only described in approximately two-third of the studies [29]. A similar percentage provided visual proof of tunnel placement. This included mostly diagrams and not actual photographs or arthroscopic pictures. In the systematic review on clinical trials, this percentage was higher, which is unexpected, since in basic science studies, it is expected to be easier to obtain imaging, dissection, and photographs (Figs. 2, 3) [29].

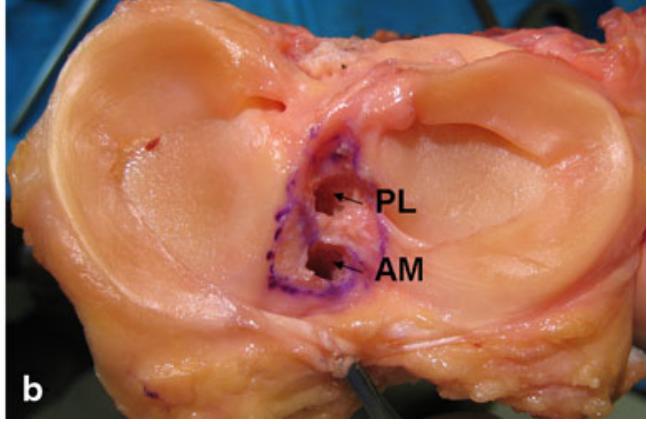

figure illustrates how tunnel and graft placement can be documented in in vitro studies. b After testing and removal of the grafts, the tunnel position can be photographed and documented as well

Half of the authors clarified or determined their femoral tunnel positions using the 'o'clock reference, instead of referring to anatomic sites. The size and shape of the ACL insertion site, tibial plateau, and femoral intercondylar notch anatomy are not the same for every patient [14]. Therefore, using the o'clock reference, provides a disservice to anatomic reconstruction methods as it provides a non-reproducible generic two-dimensional formula for tunnel placement [23]. Anatomic ACL reconstruction is, however, based on an individual approach with respect to the native anatomy [26]. The o'clock reference was originally developed to be determined on radiographs with the knee in extension and is in this manner quite reliable [32]. It was not until later that it was also utilized for arthroscopic measurements, not taking into consideration that the knee is flexed in this situation [28]. Differences in knee flection angle and viewing portal cause much confusion when using the o'clock description [28]. Another generic formula widely found in the reviewed basic science studies is the placement of tunnels at a fixed distance from another anatomic structure. However, the size and shape of the ACL varies among patients, as well as the bony morphology, causing variation in the distance between the ACL and the other structures $[14,34]$. 
Notchplasty was performed in $6 \%$ of the included studies to facilitate visualization of the posterolateral margin of the intercondylar space more clearly [3]. There are, however, significant disadvantages of notchplasty in the clinical setting, since this implies the removal of the osseous landmarks of the femoral ACL insertion, compromising anatomic tunnel placement [27], graft failure [16], and possible re-growth and overgrowth of the notch in the medium/long term [19]. This contradicts the concept of anatomic ACL reconstruction, which includes preserving the anatomy, rather than modifying it.

The increased attention to anatomic ACL reconstruction has led to a recent high number of basic science studies evaluating potential benefits and limitations of this technique $[1,2,6-8,10,12,17,18,20-22,24,30,31,33$, $36,37]$. However, the true definition of anatomic ACL reconstruction has not reached consensus, and therefore, the interpretation of "anatomic" can vary from study to study. The aim of many cadaver studies on ACL reconstruction is to study the effects of differences in reconstruction technique and tunnel position on knee biomechanics [4, 5, 11]. Recent research focuses on comparisons between anatomic and transtibial ACL reconstruction techniques $[4,5]$. Basic science is the foundation for the clinical research and ultimately treatment strategies. For the interpretation of the study results, it is therefore essential to include a detailed description of the methods, so the reader can be assured that reconstruction was indeed performed in an anatomic fashion. The ideal way to facilitate this would be to implement a standardized way of describing the anatomic technique, covering all essential aspects that define anatomic ACL reconstruction. In the interim of such a guideline, authors should strive toward a clear description of their methods, illustrated by figures documenting tunnel placement. This visual proof ascertains both accurate interpretation of data and could facilitate reproduction of the design by other authors. For readers of biomechanical studies on ACL reconstruction, the recommendation is to pay particular attention to the information given to the applied reconstruction technique and more so on what information is missing.

Biomechanical studies have shown large variations in knee kinematics after differences in surgical approach and tunnel locations [13, 30, 35]. Therefore, care should be taken to understand the methods before interpreting the findings of a study. Unsatisfactory description of the reconstruction methods in combination with the diversity of the reconstructive techniques in the reviewed biomechanical studies do not support pooling of any of the acquired data in this systematic review. Furthermore, it illustrates the need for a proper definition of "anatomic ACL reconstruction."
Overall, we found that a variety of surgical data were grossly underreported in current cadaver studies on anatomic ACL reconstruction. It might be concluded that not reported does not necessarily imply that it was not performed. However, today's high standard of medical research requires a certain degree of meticulousness when reporting methods and findings. Although surgical technique description may be most useful in clinical trials, it should also be done in detail in cadaver studies in particular as they are used as a template for clinical trials. Anatomic ACL reconstruction is performed in many different ways, which influence the outcome of the study. When the technique description is limited it makes the paper difficult to interpret and the outcome impossible to compare or pool with other existing studies. With the current discussion on single- versus double-bundle ACL reconstruction, this is especially important, since both procedures need to be performed in an anatomic fashion to show a potential benefit of one over the other.

This study delineates the lack of knowledge about anatomic ACL reconstruction and clearly demonstrates the need for a better definition, preferably a scoring system to evaluate papers on this topic. We are currently in the process of developing new scoring system for anatomic ACL reconstruction. This scoring system is expected to be used to grade ACL reconstruction procedures for individual patients as well as for review of the description of surgical methods in published studies on anatomic single- and double-bundle ACL reconstruction in clinical and cadaveric studies, and the peer review of such papers.

\section{Overall completeness and applicability of evidence}

A limitation to this review is that it was specifically focused on studies that report on an anatomic ACL reconstruction technique in an cadaver model. The authors had to report that their procedure was performed in an anatomic fashion for the study to be included. This was done since there is no clear definition available of anatomic ACL reconstruction. However, this resulted in the exclusion of studies that might have presented an anatomic reconstruction technique, but did not name it as such. Outcome data were not assessed in this systematic review due the fact that that it was not our primary goal. Moreover, the heterogeneity of the studies would make any trial to report and pool outcome measures very difficult, if not impossible.

Potential biases in the review process

The search was limited to English papers published on MEDLINE or EMBASE. Studies in other languages and published in other databases were therefore not included in 
this review. The data extraction was not performed in a blinded fashion, i.e., blacking out authors, title, and so on. However, two independent reviewers selected all the papers and extracted all the data. Furthermore, the first author validated the extracted data by processing the included studies once again after data extraction.

\section{Conclusion}

In conclusion, this systematic review of basic science studies on anatomic ACL reconstruction focused on the evaluation of the variety of reconstructive methods that have been applied. For most variables in the surgical technique description, there was gross underreporting, resulting in an inability to pool the outcomes. This study shows that "anatomic" ACL reconstruction is poorly defined; hence, new baseline studies following specific guidelines are needed in order to increase the precision and to achieve the aim of anatomic reconstruction to restore the normal function of the ACL. Until such guidelines exist, we encourage authors of these new studies to report their surgical technique in thorough manner, similar to highlevel clinical trials.

Acknowledgments The authors did not receive any outside funding related to the research presented in this paper. The department of Orthopaedic Surgery from the University of Pittsburgh receives funding from Smith and Nephew to support research related to reconstruction of the ACL.

Open Access This article is distributed under the terms of the Creative Commons Attribution Noncommercial License which permits any noncommercial use, distribution, and reproduction in any medium, provided the original author(s) and source are credited.

\section{Appendix: Search string}

(((“reconstructive surgical procedures"[MeSH Terms] OR ("reconstructive"[All Fields] AND "surgical"[All Fields] AND "procedures"[All Fields]) OR "reconstructive surgical procedures"[All Fields] OR "reconstruction"[All Fields]) OR ("surgery"[Subheading] OR "surgery"[All Fields] OR "surgical procedures, operative" [MeSH Terms] OR ("surgical"[All Fields] AND "procedures"[All Fields] AND "operative"[All Fields]) OR "operative surgical procedures"[All Fields] OR "surgery"[All Fields] OR "general surgery"[MeSH Terms] OR ("general"[All Fields] AND "surgery"[All Fields]) OR "general surgery"[All Fields])) AND (("anterior cruciate ligament" [MeSH Terms] OR ("anterior"[All Fields] AND "cruciate"[All Fields] AND "ligament"[All Fields]) OR "anterior cruciate ligament"[All Fields]) OR ACL[All
Fields])) AND ((“anatomy"[MeSH Terms] OR “anatomy"[All Fields] OR "anatomic"[All Fields]) OR ("anatomy" [MeSH Terms] OR "anatomy"[All Fields] OR "anatomical”[All Fields])) AND ("1995”[PDAT]: “2009”[PDAT]).

\section{References}

1. Albuquerque RF, Sasaki SU, Amatuzzi MM, Angelini FJ (2007) Anterior cruciate ligament reconstruction with double bundle versus single bundle: experimental study. Clinics 62:335-344

2. Arnold MP, Verdonschot N, van Kampen A (2005) ACL graft can replicate the normal ligament's tension curve. Knee Surg Sports Traumatol Arthrosc 13:625-631

3. Asahina S, Muneta T, Ezura Y (2000) Notchplasty in anterior cruciate ligament reconstruction: an experimental animal study. Arthroscopy 16:165-172

4. Bedi A, Musahl V, O'Loughlin P, Maak T, Citak M, Dixon P, Pearle AD (2010) A comparison of the effect of central anatomical single-bundle anterior cruciate ligament reconstruction and double-bundle anterior cruciate ligament reconstruction on pivot-shift kinematics. Am J Sports Med 38:1788-1794

5. Bedi A, Raphael B, Maderazo A, Pavlov H, Williams RJ 3rd (2010) Transtibial versus anteromedial portal drilling for anterior cruciate ligament reconstruction: a cadaveric study of femoral tunnel length and obliquity. Arthroscopy 26:342-350

6. Belisle AL, Bicos J, Geaney L, Andersen MH, Obopilwe E, Rincon L, Nyland J, Morgan C, Caborn DN, Arciero RA (2007) Strain pattern comparison of double- and single-bundle anterior cruciate ligament reconstruction techniques with the native anterior cruciate ligament. Arthroscopy 23:1210-1217

7. Diermann N, Schumacher T, Schanz S, Raschke MJ, Petersen W, Zantop T (2009) Rotational instability of the knee: internal tibial rotation under a simulated pivot shift test. Arch Orthop Trauma Surg 129:353-358

8. Gadikota HR, Seon JK, Kozanek M, Oh LS, Gill TJ, Montgomery KD, Li G (2009) Biomechanical comparison of single-tunneldouble-bundle and single-bundle anterior cruciate ligament reconstructions. Am J Sports Med 37:962-969

9. Higgins JPT, Greens S (2008) Cochrane handbook for systematic reviews of interventions version 5.0.2 [updated September 2009]. The Cochrane Collaboration. Available from www.cochranehandbook.org

10. Hoshino Y, Kuroda R, Nagamune K, Nishimoto K, Yagi M, Mizuno K, Yoshiya S, Kurosaka M (2007) The effect of graft tensioning in anatomic 2-bundle ACL reconstruction on knee joint kinematics. Knee Surg Sports Traumatol Arthrosc 15:508-514

11. Kato Y, Ingham SJ, Kramer S, Smolinski P, Saito A, Fu FH (2010) Effect of tunnel position for anatomic single-bundle ACL reconstruction on knee biomechanics in a porcine model. Knee Surg Sports Traumatol Arthrosc 18:2-10

12. Kilger RHP, Stehle J, Fisk JA, Thomas M, Miura K, Woo SLY (2006) Anatomical double-bundle anterior cruciate ligament reconstruction after valgus high tibial osteotomy: a biomechanical study. Am J Sports Med 34:961-967

13. Kondo E, Merican AM, Yasuda K, Amis AA (2010) Biomechanical comparisons of knee stability after anterior cruciate ligament reconstruction between 2 clinically available transtibial procedures: anatomic double bundle versus single bundle. Am J Sports Med 38:1349-1358 
14. Kopf S, Pombo MW, Szczodry M, Irrgang JJ, Fu FH (2011) Size variability of the human anterior cruciate ligament insertion sites. Am J Sports Med 39:108-113

15. Lohmander LS, Ostenberg A, Englund M, Roos H (2004) High prevalence of knee osteoarthritis, pain, and functional limitations in female soccer players twelve years after anterior cruciate ligament injury. Arthritis Rheum 50:3145-3152

16. Markolf KL, Hame SL, Hunter DM, Oakes D, Gause P (2002) Biomechanical effects of femoral notchplasty in anterior cruciate ligament reconstruction. Am J Sports Med 30:83-89

17. Markolf KL, Park S, Jackson SR, McAllister DR (2008) Simulated pivot-shift testing with single and double-bundle anterior cruciate ligament reconstructions. J Bone Joint Surg Am 90:1681-1689

18. Markolf KL, Park S, Jackson SR, McAllister DR (2009) Anteriorposterior and rotatory stability of single and double-bundle anterior cruciate ligament reconstructions. J Bone Joint Surg Am 91:107-118

19. May DA, Snearly WN, Bents R, Jones R (1997) MR imaging findings in anterior cruciate ligament reconstruction: evaluation of notchplasty. AJR Am J Roentgenol 169:217-222

20. Musahl V, Plakseychuk A, VanScyoc A, Sasaki T, Debski RE, McMahon PJ, Fu FH (2005) Varying femoral tunnels between the anatomical footprint and isometric positions: effect on kinematics of the anterior cruciate ligament-reconstructed knee. Am J Sports Med 33:712-718

21. Petersen W, Tretow H, Weimann A, Herbort M, Fu FH, Raschke M, Zantop T (2007) Biomechanical evaluation of two techniques for double-bundle anterior cruciate ligament reconstruction: One tibial tunnel versus two tibial tunnels. Am J Sports Med 35:228-234

22. Sasaki SU, Mota e Albuquerque RF, Pereira CA, Gouveia GS, Vilela JC, Alcaras Fde L (2008) An in vitro biomechanical comparison of anterior cruciate ligament reconstruction: single bundle versus anatomical double bundle techniques. Clinics 63:71-76

23. Shen W, Forsythe B, Ingham SM, Honkamp NJ, Fu FH (2008) Application of the anatomic double-bundle reconstruction concept to revision and augmentation anterior cruciate ligament surgeries. J Bone Joint Surg Am 90:20-34

24. Steckel H, Murtha PE, Costic RS, Moody JE, Jaramaz B, Fu FH (2007) Computer evaluation of kinematics of anterior cruciate ligament reconstructions. Clin Orthop Relat Res 463:37-42

25. Tashman S, Collon D, Anderson K, Kolowich P, Anderst W (2004) Abnormal rotational knee motion during running after anterior cruciate ligament reconstruction. Am J Sports Med 32:975-983

26. van Eck CF, Lesniak BP, Schreiber VM, Fu FH (2010) Anatomic single- and double-bundle anterior cruciate ligament reconstruction flowchart. Arthroscopy 26:258-268
27. van Eck CF, Morse KR, Fu FH (2009) The anteromedial portal for anterior cruciate ligament reconstruction. Arthroscopy 25:1062-1064; author reply 1064-1065

28. van Eck CF, Romanowski JR, Fu FH (2009) Anatomic singlebundle anterior cruciate ligament reconstruction. Arthroscopy 25:943-946

29. van Eck CF, Schreiber VM, Mejia HA, Samuelsson K, van Dijk CN, Karlsson J, Fu FH (2010) "Anatomic" anterior cruciate ligament reconstruction: a systematic review of surgical techniques and reporting of surgical data. Arthroscopy 26:S2-S12

30. Yagi M, Wong EK, Kanamori A, Debski RE, Fu FH, Woo SL (2002) Biomechanical analysis of an anatomic anterior cruciate ligament reconstruction. Am J Sports Med 30:660-666

31. Yamamoto Y, Hsu WH, Woo SL, Van Scyoc AH, Takakura Y, Debski RE (2004) Knee stability and graft function after anterior cruciate ligament reconstruction: a comparison of a lateral and an anatomical femoral tunnel placement. Am J Sports Med 32:1825-1832

32. Yamazaki J, Muneta T, Koga H, Sekiya I, Ju YJ, Morito T, Yagishita K (2011) Radiographic description of femoral tunnel placement expressed as intercondylar clock time in double-bundle anterior cruciate ligament reconstruction. Knee Surg Sports Traumatol Arthrosc 19:418-423

33. Yasuda K, Kondo E, Ichiyama H, Kitamura N, Tanabe Y, Tohyama H, Minami A (2004) Anatomic reconstruction of the anteromedial and posterolateral bundles of the anterior cruciate ligament using hamstring tendon grafts. Arthroscopy 20:10151025

34. Yasuda K, Tanabe Y, Kondo E, Kitamura N, Tohyama H (2010) Anatomic double-bundle anterior cruciate ligament reconstruction. Arthroscopy 26:S21-S34

35. Zaffagnini S, Bruni D, Martelli S, Imakiire N, Marcacci M, Russo A (2008) Double-bundle ACL reconstruction: influence of femoral tunnel orientation in knee laxity analysed with a navigation system-an in vitro biomechanical study. BMC Musculoskelet Disord 9:25

36. Zantop T, Diermann N, Schumacher T, Schanz S, Fu FH, Petersen W (2008) Anatomical and nonanatomical double-bundle anterior cruciate ligament reconstruction: importance of femoral tunnel location on knee kinematics. Am J Sports Med 36:678-685

37. Zavras TD, Race A, Amis AA (2005) The effect of femoral attachment location on anterior cruciate ligament reconstruction: graft tension patterns and restoration of normal anterior-posterior laxity patterns. Knee Surg Sports Traumatol Arthrosc 13:92-100 